\title{
Safe Water Community Project in Jalisco, Mexico
}

\author{
Etienne Macedo ${ }^{a}$ Michael V. Rocco ${ }^{b}$ Ravindra Mehta ${ }^{a}$ \\ Guillermo Garcia-Garciac \\ ${ }^{a}$ Department of Medicine, UCSD Medical Centre 8342, San Diego, CA, USA; ${ }^{b}$ Department of Internal Medicine, \\ Section on Nephrology, Wake Forest School of Medicine, Medical Center Blvd, Winston-Salem, NC, USA; \\ 'Nephrology Service, Hospital Civil de Guadalajara Fray Antonio Alcalde, University of Guadalajara Health Sciences \\ Center, Guadalajara, Mexico
}

\section{Keywords}

Acute kidney injury · Diarrhea · Chronic kidney disease

\begin{abstract}
Few studies have assessed kidney function in patients with gastrointestinal infections in low-resource settings. Although dehydration is a frequent complication of acute diarrhea, we do not know the frequency and severity of acute kidney injury (AKI) in this context. A high prevalence of chronic kidney disease (CKD) has been reported among the inhabitants of poor communities in Poncitlan, Mexico. Polluted drinking water has been implicated as a probable cause. These communities report a high mortality associated with gastrointestinal infection. It is possible that a high incidence of waterborne disease and consequent more episodes of AKI might contribute to the high prevalence of CKD in this population. In this study, we aim to determine the association between the use of unsafe water and the incidence of acute diarrhea and AKI, and to determine if the provision of clean water decreases these complications. The study will be conducted in 3 communities of the municipality of Poncitlan. Initially, we will determine the water, sanitation, and hygiene (WASH) characteristics in the population and evaluate the incidence of diarrheal disease. In the observation phase, outcomes will be assessed after families receive train-
\end{abstract}

ing in WASH techniques, but before they are provided with clean water. In the intervention phase, outcomes will be assessed after clean water is provided.

(C) 2019 The Author(s)

Published by S. Karger AG, Basel

\section{Introduction}

The Global Burden of Disease study estimated that diarrhea was a leading cause of death among all ages: 1.31 million deaths, in 2015 [1]. Several studies have implicated diarrhea as a risk factor for malnutrition and impaired physical growth, and some have suggested that it might also impair cognitive development [2]. Approximately $88 \%$ of diarrhea-associated deaths are attributable to unsafe water, inadequate sanitation or insuffient hygiene, and approximately 2.4 billion people globally have no access to basic sanitation $[3,4]$. Microbial contamination is widespread in lower- and middle-income countries and affects all water source types, including piped supplies. Guidelines for Drinking-Water Quality recommend that fecal indicator bacteria, preferably E. coli or alternatively thermotolerant coliforms, should not be detectable in any $100 \mathrm{~mL}$ drinking water sample (WHO 2011) [5]. Approximately 1.8 billion people globally use a source of drinking

\section{KARGER}

E-Mail karger@karger.com www.karger.com/anm
(C) 2019 The Author(s) Published by S. Karger AG, Basel

Karge Open access

This article is licensed under the Creative Commons AttributionNonCommercial-NoDerivatives 4.0 International License (CC BY NC-ND) (http://www.karger.com/Services/OpenAccessLicense). Usage and distribution for commercial purposes as well as any distribution of modified material requires written permission.
Guillermo Garcia-Garcia

Nephrology Service, Hospital Civil de Guadalajara Fray Antonio Alcalde University of Guadalajara Health Sciences Center

Hospital 278, Guadalajara, Jalisco 44280 (Mexico)

E-Mail ggarcia1952@gmail.com 
Table 1. Socioeconomic indicators of affected communities

\begin{tabular}{llrlllrr}
\hline & $\begin{array}{l}\text { Marginality } \\
\text { index }\end{array}$ & Population, $n$ & Illiterate, \% & $\begin{array}{l}\text { Incomplete primary } \\
\text { school, \% }\end{array}$ & $\begin{array}{l}\text { Households without } \\
\text { sewage system, \% }\end{array}$ & $\begin{array}{l}\text { Households without } \\
\text { running water, \% }\end{array}$ & $\begin{array}{l}\text { Households with } \\
\text { dirt floor, \% }\end{array}$ \\
\hline Poncitlan & Medium & 40,827 & 7.3 & 23.4 & 1.2 & 5.2 & 3.4 \\
San Pedro ltzican & High & 4,478 & 21.6 & 47.9 & 5.3 & 4.6 & 2.3 \\
Mezcala & High & 3,896 & 10.5 & 35.5 & 3.0 & 40.4 & 10.2 \\
Agua Caliente & High & 988 & 7.79 & 40.8 & 28.7 & 15.0 \\
\hline
\end{tabular}

Data from references [11, 12].

water that suffers from fecal contamination; of these, 1.1 billion drink water that is of at least "moderate" risk ( $>10$ E. coli or thermotolerant coliforms per $100 \mathrm{~mL}$ ).

Acute kidney injury (AKI) is a frequent complication of acute diarrhea and gastrointestinal infections [6], but very few studies have assessed kidney function in patients with gastrointestinal infections in low-resource areas and rural communities with no or very limited access to health care $[7,8]$. The impact of AKI development on the shortand long-term outcomes in patients with diarrheal disease is unknown.

In this project, we aim to determine the incidence of gastroenteritis, waterborne diseases, and AKI in 3 communities that have a high penetration of unsafe water and to evaluate the effect of safe water provision on these issues. We have selected 3 communities from the municipality of Poncitlan, Jalisco, Mexico, based on the high prevalence of gastroenteritis and waterborne disease and the knowledge of the water utilization source. We will partner with the Secretaria de Salud Jalisco (SSJ), in order to obtain information on the quality of water and baseline data on the epidemiology of gastroenteritis and waterborne disease.

The study will be conducted in the communities of San Pedro Itzican, Mezcala, and Agua Caliente located along the Lake Chapala lakeshore in the municipality of Poncitlan. In these communities, water quality has been an issue for many years. Lake Chapala is the ultimate receptor of a great variety of contaminants, including pesticides, industrial residues, and heavy metals such as chromium, lead, zinc, and mercury. Local sources of pollution are also visible [9]. The absence of an adequate sewer system causes Chapala lake water to be contaminated. Wells drilled to avoid the use of lake water did not resolve the issue, as water from wells is contaminated by water springs with a high content of arsenic and other harmful elements. Over the years, these communities have shown a high mortality rate, secondary to intestinal infection and malnutrition [10]. The socioeconomic indicators in these communities show an alarming high marginality index, a high illiteracy rate, and incomplete primary school rates; a large percentage of households lack both a sewage system and tap water, and a high percentage of homes have dirt floors $[11,12]$ (Table 1).

These communities have a high prevalence of chronic kidney disease (CKD) of unknown etiology. Popular opinion in the lay media has implicated polluted drinking water as a probable cause [13]. Since 2006, the Hospitales Civiles Foundation has used mobile units to assess the presence of CKD in the state of Jalisco. Trained personnel using mobile units travel to rural and urban areas to collect demographic and clinical data, in addition to blood and urine samples for serum chemistry and dipstick urinalysis [14]. This screening program has shown a high prevalence of CKD (estimated glomerular filtration rate $<60 \mathrm{~mL} / \mathrm{min} / 1.73 \mathrm{~m}^{2}$ ) and proteinuria in Poncitlan, twofold and 3-fold higher, respectively, as compared to the adult population in other Jalisco municipalities [15]. In children, although the prevalence of CKD was similar to other Jalisco municipalities, the prevalence of proteinuria was 10 times higher [16]. Similarly, a recent cross-sectional study in children residing in these communities reported a prevalence of albuminuria and CKD of $45 \%$ and $33 \%$, respectively; these rates of albuminuria are 3-5 times higher than reported in the state of Jalisco and the international literature [17]. Information from Jalisco's vital statistics shows a high prevalence of intestinal infection, associated with a high mortality rate among children under 5 years of age [10]. It is possible that a high incidence of waterborne disease, and consequently more frequent episodes of AKI, contribute to the high prevalence of proteinuria and CKD in this population. The role of heavy metals and other contaminants in the water may also be important determinants of this outcome [9].

The primary objectives of the study are to evaluate the association between safe water provision and gastroenteritis frequency, waterborne diseases, and kidney disease in 


\begin{tabular}{|c|c|c|c|}
\hline Months 1-3 & Month 4 & \multicolumn{2}{|c|}{ Months 5-12 } \\
\hline \multicolumn{2}{|c|}{ Pre-implementation phase } & \multicolumn{2}{|c|}{ Implementation phase } \\
\hline Setting up & Training & Observation phase & Intervention phase \\
\hline \multirow{3}{*}{$\begin{array}{l}\text { - Acquire data from water } \\
\text { quality and baseline } \\
\text { incidence of } \\
\text { gastroenteritis, water } \\
\text { borne diseases and acute } \\
\text { kidney disease } \\
\text { - Institutional review board } \\
\text { study approval } \\
\text { - Sign agreements among } \\
\text { institutions and staff } \\
\text { - Discuss communication } \\
\text { protocols with health care } \\
\text { directors and staff }\end{array}$} & \multirow{3}{*}{$\begin{array}{l}\text { - Research coordinators } \\
\text { trained in: } \\
\checkmark \text { WASH techniques } \\
\checkmark \text { Communication } \\
\text { protocol and risk } \\
\text { assessment instrument } \\
\checkmark \text { POC tests ( } \mathrm{SCr} \text {, urinalysis) } \\
\text { - Test checklist and } \\
\text { decision flow chart for } \\
\text { monitoring }\end{array}$} & & $\begin{array}{l}\text { WASH training for } \\
\text { families among the } \\
\text { communities }\end{array}$ \\
\hline & & & $\begin{array}{l}\text { Provision of clean } \\
\text { water for the three } \\
\text { communities of } \\
\text { Poncitlan }\end{array}$ \\
\hline & & \multicolumn{2}{|c|}{$\begin{array}{l}\text { - Prospective collection of data utilizing customized } \\
\text { mobile interface device with capability to connect to } \\
\text { project database } \\
\text { - Use of point-of-care based for risk assessment } \\
\text { - Assessment of patient outcomes and process of care }\end{array}$} \\
\hline
\end{tabular}

Fig. 1. Study overview. WASH, water, sanitation and hygiene; POC, point of care; sCr, serum creatinine.

these communities. We have hypothesized that the use of unsafe water is associated with an increased incidence of gastroenteritis and waterborne diseases and leads to high prevalence of AKI. We aim to determine the frequency of AKI in patients with diarrheal disease based on serum creatinine $(\mathrm{sCr})$ and biomarkers of kidney injury. Our secondary objectives are to determine the barriers for safe water use, to determine the association between water, sanitation, and hygiene (WASH) parameters and the prevalence of diarrheal illness. In addition, we will assess the effect of an educational strategy for WASH on diarrheal illness.

\section{Materials and Methods}

\section{Preimplementation Phase}

The study will be conducted in the communities of San Pedro Itzican, Mezcala, and Agua Caliente located along the Lake Chapala lakeshore in the municipality of Poncitlan, with a total population of approximately 10,000 individuals. Before study implementation, we will determine the WASH characteristics in the target population and evaluate the incidence of diarrheal disease in these communities. Following authorization from the SSJ and study approval from the Hospital Civil de Guadalajara Ethics and Research Committee, we will acquire data on water quality at different levels of distribution and utilization. Communication protocols among health-care facilities, families, and research coordinators will be established via the SSJ. We will train research coordinators in WASH techniques, in the validated risk assessment instrument, the performance of point of care (POC) tests, and for the collection and processing of serum and urine samples for storage for future biomarker assessment. All health providers and relevant staff will be trained in the protocol-based management of diarrheal disease and AKI that is appropriate to the setting in which they work. Providers will also be educated regarding the use of oral rehydration fluids for the treatment of dehydration, following the guidelines of Mexico's Ministry of Health [18]. The SSJ will help to coordinate these training sessions. All families will be taught WASH best practices (Fig. 1).

\section{Implementation Phase}

The implementation phase will consist of 2 parts. During the observation (first) phase, study outcomes will be assessed after families receive training in WASH techniques, but before they are provided with clean water. During the intervention (second) phase, study outcomes will be assessed after clean water is provided to the community.

\section{Observation Phase}

Patients with signs and symptoms of diarrheal disease will be encouraged to contact the local health-care center and/or study research coordinator. Patients with CKD stage 5 or in chronic dialysis and those with solid organ transplant will not be candidates for study participation. Patients meeting these criteria will be screened by the research coordinator and asked for consent. $\mathrm{Pa}$ tients (or surrogates) who sign informed consent will have a POC test for $\mathrm{s} \mathrm{Cr}$ and urinalysis by dipstick.

The results of the POC tests will be given to the health-care provider, who will be responsible for informing the patient of the results. The health-care provider will be given the accepted normal range of values for adults and children (adults: sCr $0.6-1.2 \mathrm{mg} / \mathrm{dL} ; 53-105$ $\mu \mathrm{mol} / \mathrm{L}$ [19]; children $0-12$ years old $0.0-0.7 \mathrm{mg} / \mathrm{dL} ; 0-62 \mu \mathrm{mol} / \mathrm{L}$, I) [20]. The health-care provider, however, will decide if the results are in the normal range according to the normative values and patient's comorbidities, age, and overall health characteristics. All health-care decisions will be made by the local health authorities. 
Fig. 2. Study flow during implementation phase. WASH, water, sanitation, and hygiene; POC, point of care; sCr, serum creatinine.

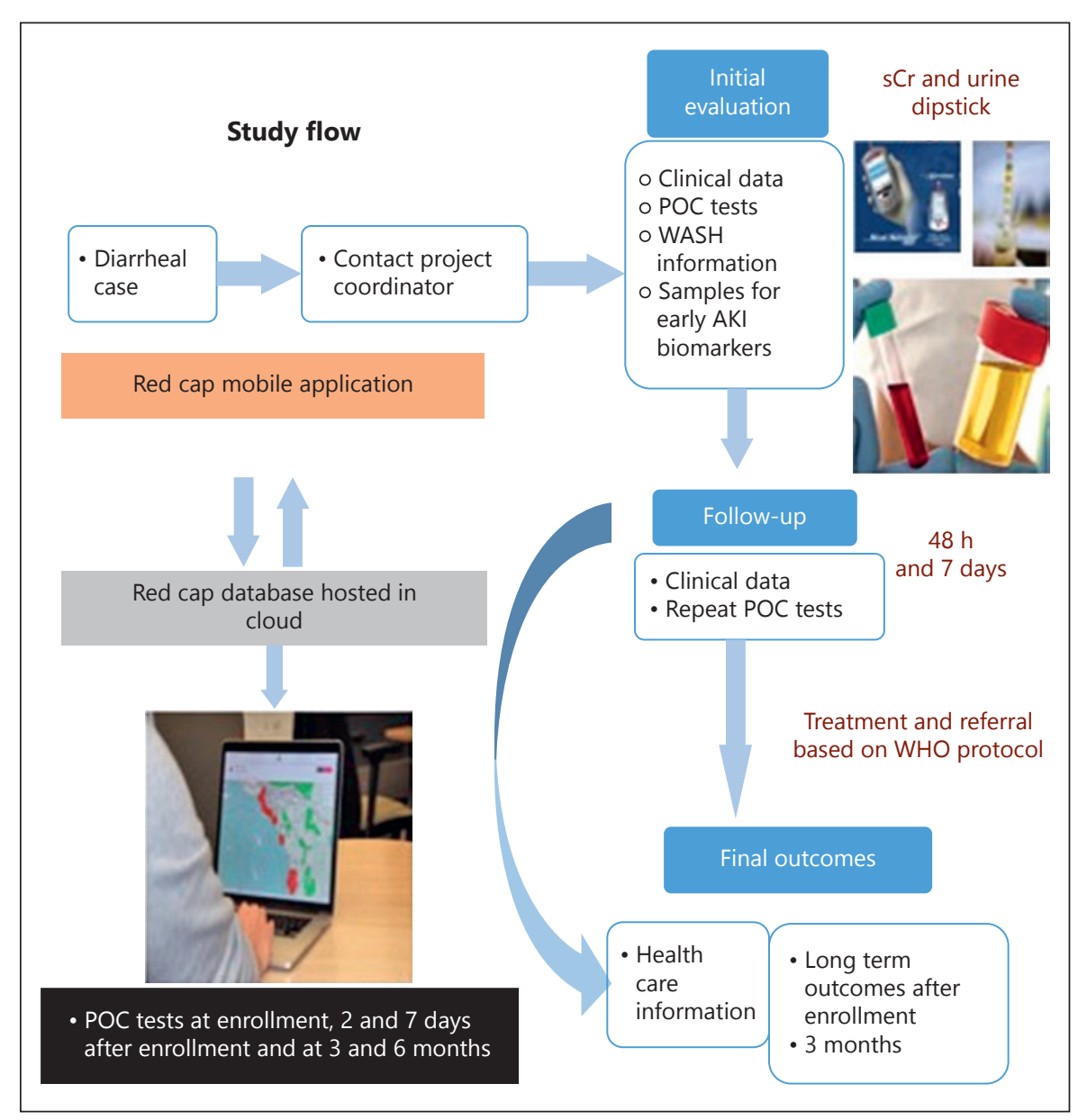

Blood and urine samples will be collected and stored for future biomarker analysis (Table 2). All enrolled patients will complete a clinical and WASH assessment and will be tracked throughout their clinical course by location (i.e., health-care center, hospital, and home). Outcomes will be recorded for 3 months following the initial health-care evaluation.

Patient level data will be tracked by the project research coordinator via communication with health-care facilities and families in the community. All relevant clinical data and the results of the POC test will be recorded in the electronic case report forms. Data will be recorded using the Red Cap Mobile Application. All captured information will be kept in a data repository site. The forms in Red Cap Mobile APP will be adapted for use in the community setting to capture data on the incidence, management and outcomes associated with diarrheal disease, dehydration, and AKI (Fig. 2).

\section{Intervention Phase}

In the second phase of the study, safe water will be distributed to the communities. We will repeat research coordinator and health provider training for the protocol-based management of diarrheal disease and AKI. The same study flow will be in place, and we will compare the incidence and severity of diarrheal diseases and patient outcomes. We will analyze the incidence of diarrheal disease and AKI based on whether or not patient and families are following WASH and also by water source.
Table 2. Study schedule and measurements for implementation phase

\begin{tabular}{|c|c|c|c|c|}
\hline & \multicolumn{4}{|l|}{ Time point } \\
\hline & enrollment & $48 \mathrm{~h}$ & 7 days & 3 months \\
\hline \multicolumn{5}{|l|}{$\begin{array}{l}\text { Medical history and } \\
\text { physical assessment }\end{array}$} \\
\hline Physical exam & $\times$ & $x$ & $\times$ & $x$ \\
\hline Blood pressure & $\times$ & $x$ & $x$ & $x$ \\
\hline Medication review & $\times$ & $x$ & $\times$ & $x$ \\
\hline \multicolumn{5}{|l|}{ Renal functional assessment } \\
\hline POC test $\mathrm{sCr}$ & $\times$ & $x$ & $\times$ & $x$ \\
\hline Urinalysis & $\times$ & $x$ & $\times$ & $x$ \\
\hline \multicolumn{5}{|l|}{ Urine and blood collection } \\
\hline $\begin{array}{c}\text { Biorepository for } \\
\text { biomarkers }\end{array}$ & $\times$ & $x$ & $\times$ & $x$ \\
\hline \multicolumn{5}{|l|}{ Other assessments } \\
\hline Weight and height & $\times$ & & & $x$ \\
\hline WASH questionnaire & $\times$ & & & $x$ \\
\hline
\end{tabular}

POC, point of care; sCr, serum creatinine; WASH, water, sanitation and hygiene. 
Health-care providers will track patient clinical status and renal outcomes at $48 \mathrm{~h}, 7$ days, and 3 months after enrollment. Urine and serum samples will be collected at all follow-up time points.

\section{Analytical Plan}

\section{Observation Phase}

We will capture data on the course of patients with signs and symptoms of diarrheal disease and gastrointestinal infections. During this phase, we will define the gaps in knowledge and local barriers for WASH techniques and use of clean water. We will determine the frequency of specific risk factors for acute and CKDs. We will describe the WASH characteristics of the families enrolled in the study and correlate them with patient characteristics and risk factors for kidney diseases. We expect to establish the baseline frequency of AKI development, progression to more severe stages of AKI, and development of CKDs. Based on preliminary data from the SSJ, we anticipate that we will need to enroll 200 patients during this phase in order to obtain an adequate data sample (Table 2).

\section{Intervention Phase}

Safe drinking water will be provided for the 3 communities. We will evaluate the penetration and the barriers to use of safe water. We will compare the frequency of diarrheal disease, AKI, and severity of renal dysfunction between the observation and intervention phases. We will perform an interim analysis after the enrollment of 200 patients and 400 patients during this phase. We will continue this phase in the second and third year, aiming to complete enrollment of 800 patients, if the interim analysis does not indicate a need for early cessation of the study.

After study completion, we will assess the serum and urine samples for biomarkers of glomerular and tubular function. We will assess a panel of tubular markers repre- senting concentration, reabsorption, and secretion function, which correlate with AKI severity or CKD progression (Table 2). The sequential assessment of these biomarkers, at initiation and during the course of the disease process, will provide us with a unique opportunity to understand their pattern of change during gastrointestinal diseases with and without AKI. We will evaluate how these changes correlate with AKI development, severity, and recovery.

\section{Conclusion}

In summary, the study will provide an opportunity (a) to demonstrate that the use of unsafe water is associated with an increased incidence of gastroenteritis and waterborne diseases leading to episodes of AKI and (b) to determine if the provision of clean water to communities with high penetration of polluted water is associated with a decreased incidence of these complications.

\section{Statement of Ethics}

Subjects (or their parents or guardians) will give their written informed consent. The study has been submitted for approval to the Hospital Civil de Guadalajara Fray Antonio Alcalde Ethics and Research Committee.

\section{Disclosure Statement}

The authors have no conflicts of interest to declare. E.M., M.V.R., and G.G.-G. received travel expenses and registration fee from Danone Research to participate in the 2018 Hydration for Health Scientific Conference. All authors have contributed to the conception and design of the work and will equally contribute to the acquisition, analysis, and interpretation of data; drafting the work; approving the version to be published; and will be accountable for all aspects of the work.

\section{References}

1 Collaborators GD; GBD Diarrhoeal Diseases Collaborators. Estimates of global, regional, and national morbidity, mortality, and aetiologies of diarrhoeal diseases: a systematic analysis for the Global Burden of Disease Study 2015. Lancet Infect Dis. 2017 Sep;17(9): 909-48.

2 Richard SA, Black RE, Gilman RH, Guerrant RL, Kang G, Lanata CF, et al.; Childhood
Malnutrition and Infection Network. Diarrhea in early childhood: short-term association with weight and long-term association with length. Am J Epidemiol. 2013 Oct; 178(7):1129-38.

3 Group CM; Child Mortality Coordination Group. Tracking progress towards the Millennium Development Goals: reaching consensus on child mortality levels and trends.
Bull World Health Organ. 2006 Mar;84(3): 225-32.

4 Prüss-Ustün A, Bartram J, Clasen T, Colford JM Jr, Cumming O, Curtis V, et al. Burden of disease from inadequate water, sanitation and hygiene in low- and middle-income settings: a retrospective analysis of data from 145 countries. Trop Med Int Health. 2014 Aug; 19(8):894-905. 
5 WHO. Water, Sanitation and Hygiene. Assessing microbial safety for drinking water: improving approaches and methods. London: IWA Publishing; 2003.

6 Jha V, Parameswaran S. Community-acquired acute kidney injury in tropical countries. Nat Rev Nephrol. 2013 May;9(5):27890.

7 Susantitaphong P, Cruz DN, Cerda J, Abulfaraj M, Alqahtani F, Koulouridis I, et al.; Acute Kidney Injury Advisory Group of the American Society of Nephrology. World incidence of AKI: a meta-analysis. Clin J Am Soc Nephrol. 2013 Sep;8(9):1482-93.

8 Mehta RL, Cerdá J, Burdmann EA, Tonelli M, García-García G, Jha V, et al. International Society of Nephrology's 0by25 initiative for acute kidney injury (zero preventable deaths by 2025): a human rights case for nephrology. Lancet. 2015 Jun;385(9987):2616-43.

9 Stong T, Alvarado Osuna C, Shear H, de Anda Sanchez J, Ramírez G, Díaz Torres Jde J. Mercury concentrations in common carp (Cyprinus carpio) in Lake Chapala, Mexico: a lakewide survey. J Environ Sci Health A Tox Hazard Subst Environ Eng. 2013;48(14):1835-41.
10 Jalisco SdS. Indicadores de Mortalidad por Enfermedades Infecciosas Intestinales en Menores de 5 años. Secretaria de Salud Jalisco, 2013; 2017.

11 Geografica IdIEy: Poncitlan. Diagnostico del Municipio. Jalisco, Mexico. Instituto de Informacion Estadistica y Geografica 2016; 2017.

12 Agua Caliente. Mexico, PueblosAmerica. com; 2019.

13 Spechler D. Under the Surface. Investigating chronic kidney disease in Jalisco, Mexico. Browsings. New York, N.Y.: Harper's Magazine; 2017.

14 Gutierrez-Padilla JA, Mendoza-Garcia M, Plascencia-Perez S, Renoirte-Lopez K, Garcia-Garcia G, Lloyd A, et al. Screening for $\mathrm{CKD}$ and cardiovascular disease risk factors using mobile clinics in Jalisco, Mexico. Am J Kidney Dis. 2010 Mar;55(3):474-84.

15 Garcia-Garcia G, Morraz-Mejia F, Montalban $J M$, Chavez-Iñiguez J, Vazquez-Martinez L, Nungaray E, et al. CKDu in Mexico: The Case of Poncitlan, Jalisco. J Am Soc Nephrol. 2017; 28:67A.
16 Garcia-Garcia G, Rubio R, Amador M, Ibarra-Hernandez M, De la Torre-Campos L, Romero A, et al. CKDu in Mexican Children: The Case of Poncitlan. J Am Soc Nephrol. 2017;28:767.

17 Lozano-Kasten F, Sierra-Diaz E, de Jesus Celis-de la Rosa A, Margarita Soto Gutiérrez M, Aarón Peregrina Lucano A. Childhood RGoSaEDi: Prevalence of Albuminuria in Children Living in a Rural Agricultural and Fishing Subsistence Community in Lake Chapala, Mexico. Int J Environ Res Public Health. 2017:14.

18 Prevención, diagnóstico y tratamiento de la enfermedad diarreica aguda en niños de dos meses a cinco años en el primero y segundo nivel de atención. Mexico City: Secretaria de Salud; 2008.

19 Shephard MD. Point-of-Care Testing and Creatinine Measurement. Clin Biochem Rev. 2011;32:109-14.

20 Boer DP, de Rijke YB, Hop WC, Cransberg K, Dorresteijn EM. Reference values for serum creatinine in children younger than 1 year of age. Pediatr Nephrol. 2010 Oct;25(10):210713. 